\title{
Design and Analysis of Triple-Band Inverted F-slot Microstrip Patch Antenna
}

\author{
Swaraj Panusa \\ University College of Engineering \\ RTU, Kota (Rajasthan), India
}

\author{
Mithilesh Kumar \\ University College of Engineering \\ RTU, Kota (Rajasthan), India
}

\begin{abstract}
Microstrip patch antennas are strong candidates for use in many wireless communications applications. Microstrip patch antennas are also highly preferable for multiband as well as for the WiMAX application. In this paper, a multi-band H-slot microstrip patch antenna for Worldwide Interoperability for Microwave Access (WiMAX) is presented. The radiation performance such as VSWR, return loss, radiation pattern and gain of the antenna are simulated using Ansoft HFSS, fabricated and then presented. This antenna has a simpler structure than other antennas designed for realizing multiband characteristics which is just composed of a coaxial feed line, a substrate, and a ground plane. Radiating patch lies on the FR4_epoxy substrate which is having dielectric constant 4.1 and height $1.5 \mathrm{~mm}$. Coaxial feeding technique is used to feed the antenna with $50 \mathrm{ohm}$ impedance. This proposed antenna enhances the maximum return loss of $-17.79 \mathrm{~dB}$ at $5.55 \mathrm{GHz},-24.16 \mathrm{~dB}$ at $6.55 \mathrm{GHz}$ and $-25.55 \mathrm{~dB}$ at $7.40 \mathrm{GHz}$ frequencies. Computer simulated results showing the VSWR value lesser than two for the frequency range of 5.40-5.60 $\mathrm{GHz}, 6.45-6.22 \mathrm{GHz}$ and 7.35-7.50 GHz. Simulated and fabricated results are very much similar.
\end{abstract}

\section{Keywords}

Triple-band; Microstrip Patch Antenna; F-Slot; WiMAX; WLAN; Radiation pattern.

\section{INTRODUCTION}

Communication can be broadly defined as the transfer of information from one point to another. Communication between human beings was first done through voice. With the desire to increase the distance of communication, devices such as Drums, signal flags and smoke were used. It has been of recent in human history that the electromagnetic spectrum, outside the visible region has been employed for communication, through the use of Radio. One of the greatest human scientific evolutions is the emergence of electromagnetic spectrum and antenna has been instrumental in harnessing the resource [1]-[4]. Antenna plays a very important part in any wireless communication systems. Complexity is reduced and the performance of the receiver is enhanced by the well-designed antenna. Based on the application and the operating frequency of the antenna, the dimension, type and the configuration of the antenna will be chosen. In modern wireless communication systems, multiband antenna has been playing a very important role for wireless service requirements [5]-[9].

Microstrip patch antennas are highly preferable for multiband as well as for the WiMAX and WLAN application. Microstrip patch antenna is very important for antenna designer because of its advantage such as low cost, simple configuration, ease of fabrication, mechanically rugged and compatibility with integrated circuits. Microstrip patch antennas are well suited for high frequency applications because the size of the antenna depends on wavelength and resonant frequency. Microstrip patch antennas are highly preferable for multiband as well as for the WiMAX application [10]-[19].

In this paper, a triple band inverted F-slot microstrip patch antennas for WiMAX application is design and analyses. Further fabrication is performed by using MIC technology. The antenna covers three frequency bands of $5.40-5.60 \mathrm{GHz}$, 6.45-6.62 $\mathrm{GHz}$ and 7.35-7.50 GHz.

\section{ANTENNA DESIGN}

Substrate selection is the first practical step in designing a patch antenna. FR4_epoxy (dielectric constant $=4.1$ and height $=1.5 \mathrm{~mm}$ ) is used as substrate to design, simulate and fabricate the proposed triple band inverted F-slot microstrip patch antenna. To feed the proposed microstrip patch antenna a coaxial probe of characteristic impedance $50 \mathrm{ohm}$ is used. The study of varies parameters summarizes the relationship between antenna dimension and its associated effect on antenna performance. The antenna dimensions obtained after necessary tuning on single antenna element are shown in table 1.

Table 1. Dimensions of the proposed inverted F-slot microstrip patch antenna

\begin{tabular}{cccccccc}
\hline \hline Parameter & $L$ & $W$ & $L s$ & $W s$ & $a$ & $b$ & $y_{f}$ \\
\hline Units $(\mathrm{mm})$ & 34 & 27 & 28.25 & 12 & 2 & 2 & 5.5 \\
\hline \hline
\end{tabular}

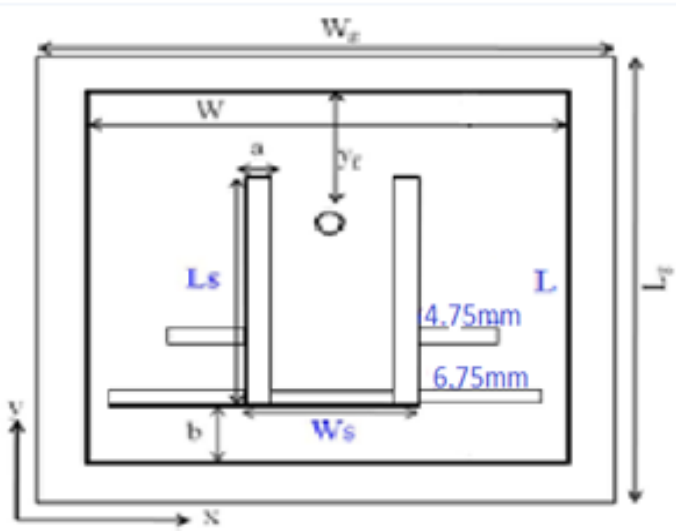

(a)

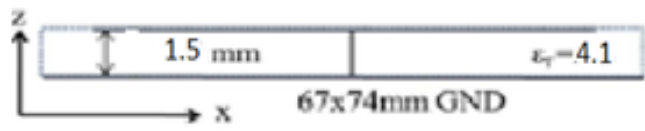

(b)

Fig 1: Geometry of the proposed inverted F-slot microstrip antenna: (a) top view (b) side view 


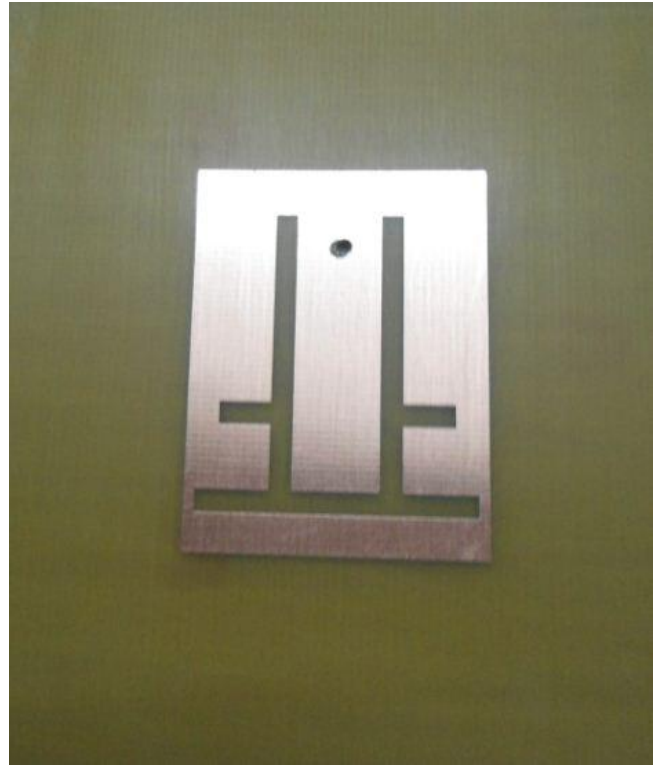

(a)

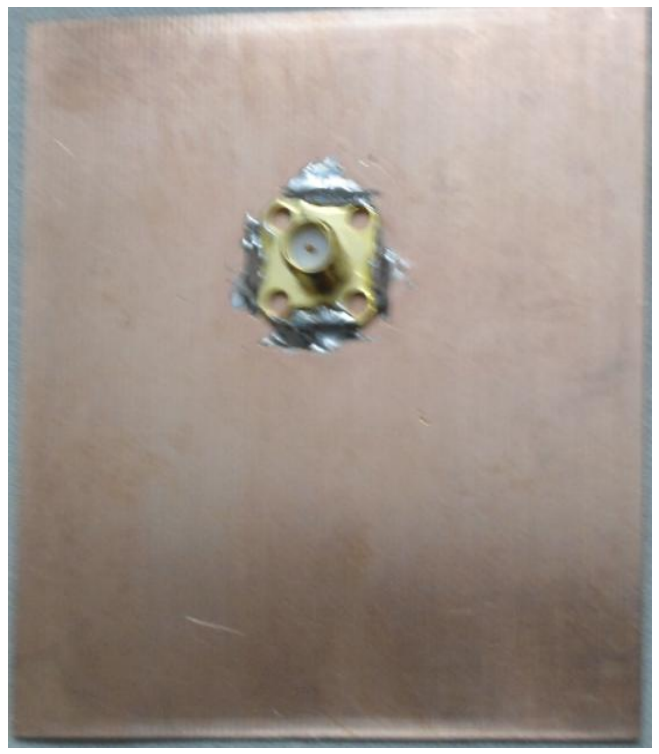

(b)

Fig 2: Hardware of the proposed F-slot microstrip patch antenna (a)top view (b)bottom view

\section{EXPERIMENTAL RESULTS AND DISCUSSION}

In this section, first of all the simulation and analysis is done for the proposed triple band inverted F-slot microstrip patch antenna by Ansoft HFSS. From these simulation results, the parametric studies are carried out. Further we fabricate this designed inverted F-slot antenna using MIC technology and results are measured with the help of Agilent vector network analyzer E5071C ENA series (300 KHz-20 GHz).

The prototype of the proposed antenna in Fig. 1 was fabricated and investigated experimentally. A photo of the proposed antenna prototype is shown in Fig. 2. The antenna overall size is $67 \mathrm{~mm} \times 74 \mathrm{~mm} \times 1.5 \mathrm{~mm}$. The proposed antenna have impedance matching better than $-10 \mathrm{~dB}$ return loss for frequency range of $5.40-5.60 \mathrm{GHz}, 6.45-6.62 \mathrm{GHz}$ and 7.35 $7.50 \mathrm{GHz}$ respectively. Fig. 3 shows the current distribution in the patch of the proposed antenna. Fig. 4 shows that the antenna have the maximum return loss of $-17.79 \mathrm{~dB}$ at 5.55 $\mathrm{GHz},-24.16 \mathrm{~dB}$ at $6.55 \mathrm{GHz}$ and $-25.55 \mathrm{~dB}$ at $7.40 \mathrm{GHz}$. From Fig. 4 we can easily compare our simulated and measured results. Fig. 5 shows the VSWR value lesser than 2 for the frequency range of 5.40-5.60 GHz, $6.45-6.62 \mathrm{GHz}$ and 7.35-7.50 GHz respectively. Fig. 5 we can easily compare our simulated and measured VSWR. By seeing both Fig. 4 and Fig. 5 we get that our simulated and measured result are very much same and good enough for wireless applications. Fig. 6 shows the simulated $2 \mathrm{D}$ radiation pattern at $5.55 \mathrm{GHz}, 6.55$ $\mathrm{GHz}$ and $7.40 \mathrm{GHz}$ frequency respectively. Fig. 7 shows the simulated 3D radiation pattern at $5.55 \mathrm{GHz}, 6.55 \mathrm{GHz}$ and $7.40 \mathrm{GHz}$ frequency respectively, having maximum gain of $2.23,4.19$ and 2.72 at $5.55 \mathrm{GHz}, 6.55 \mathrm{GHz}$ and $7.40 \mathrm{GHz}$ frequency respectively.

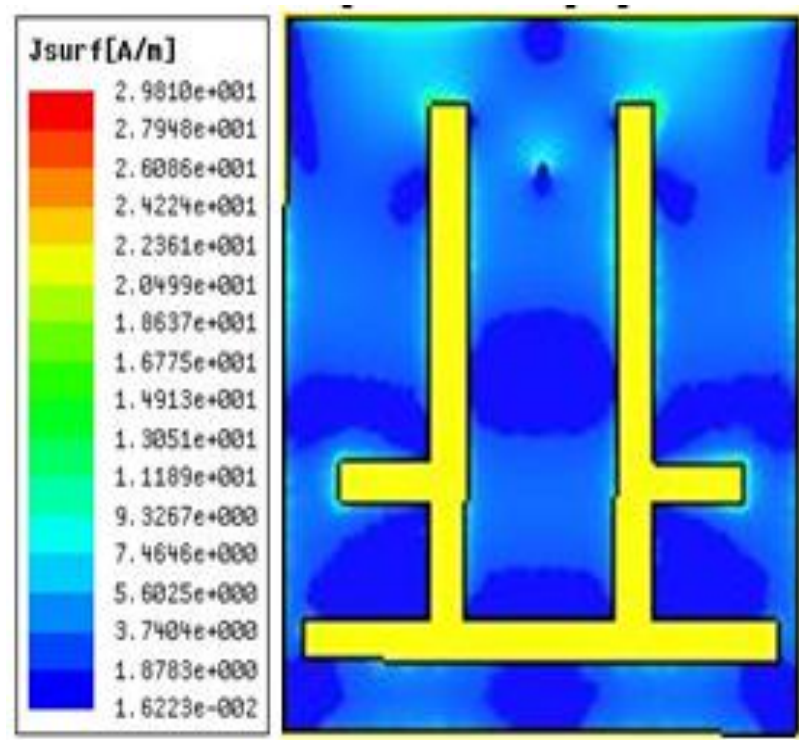

Fig 3: Current distribution in the patch of the proposed antenna

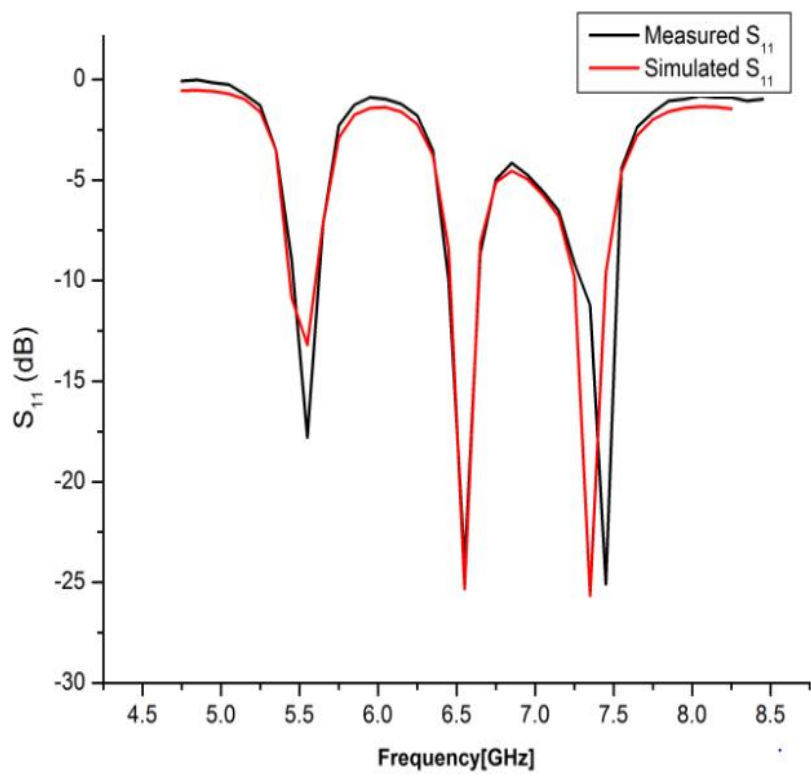

Fig 4: Comparison of simulated and measured return-loss of the proposed antenna 


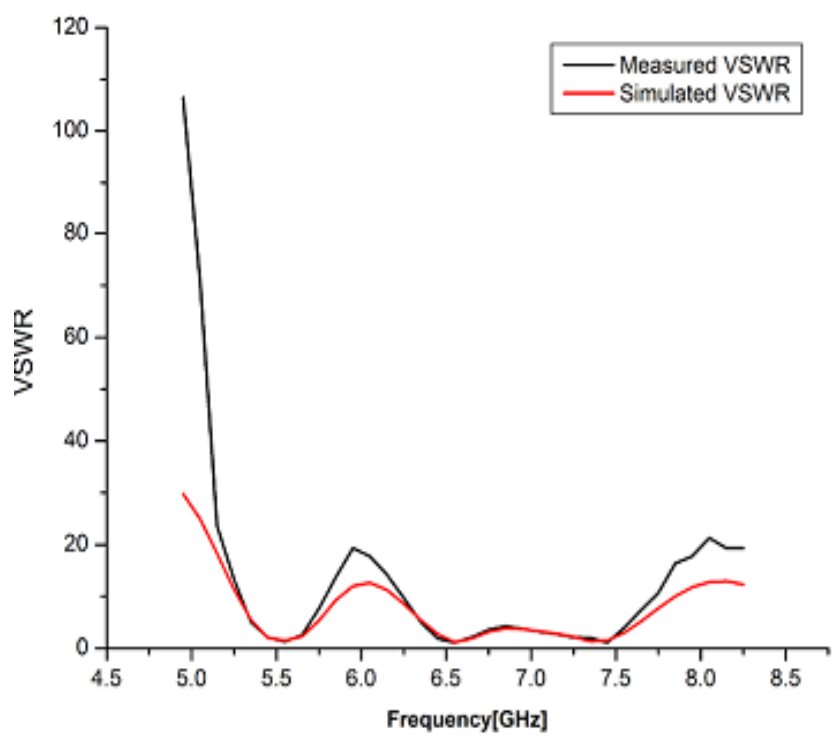

Fig 5: Comparison of simulated and measured VSWR of the proposed antenna

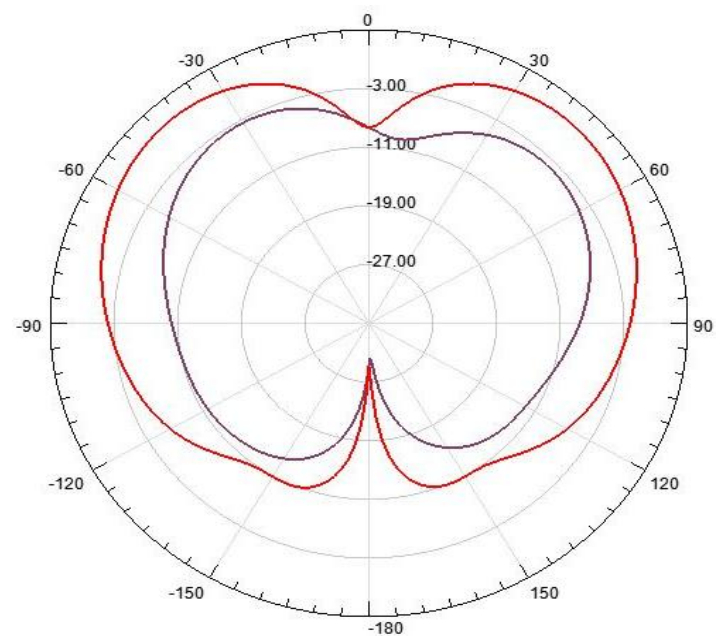

(a)

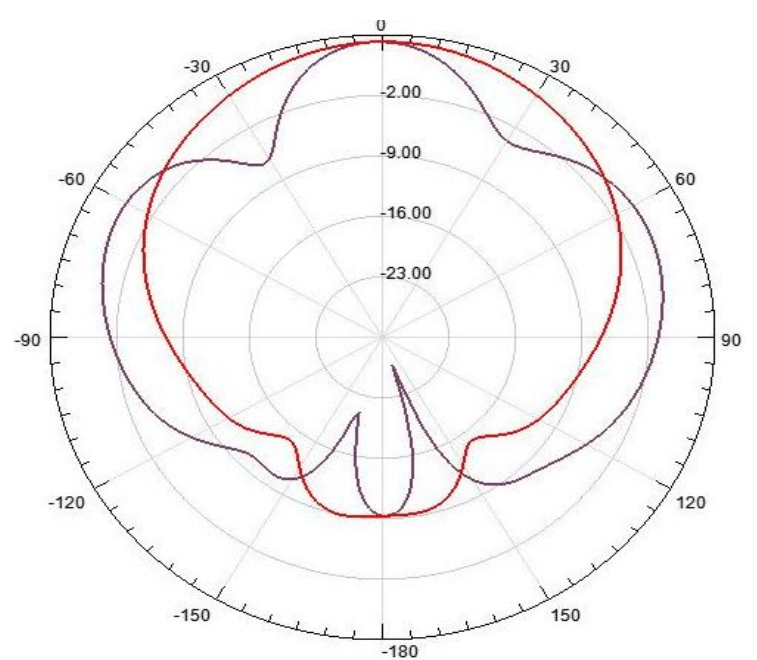

(b)

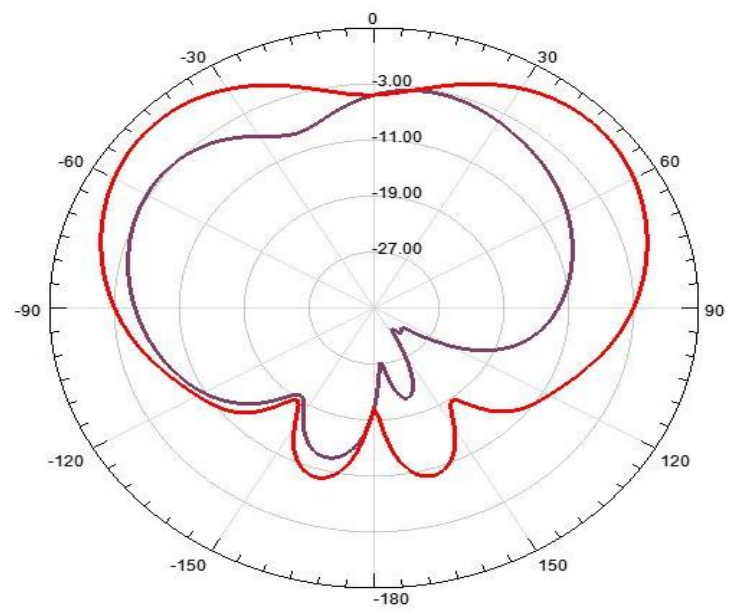

(c)

Fig 6: Simulated 2D Radiation pattern of the proposed antenna at (a) $5.55 \mathrm{GHz}$ (b) $6.55 \mathrm{GHz}$ (c) $7.40 \mathrm{GHz}$
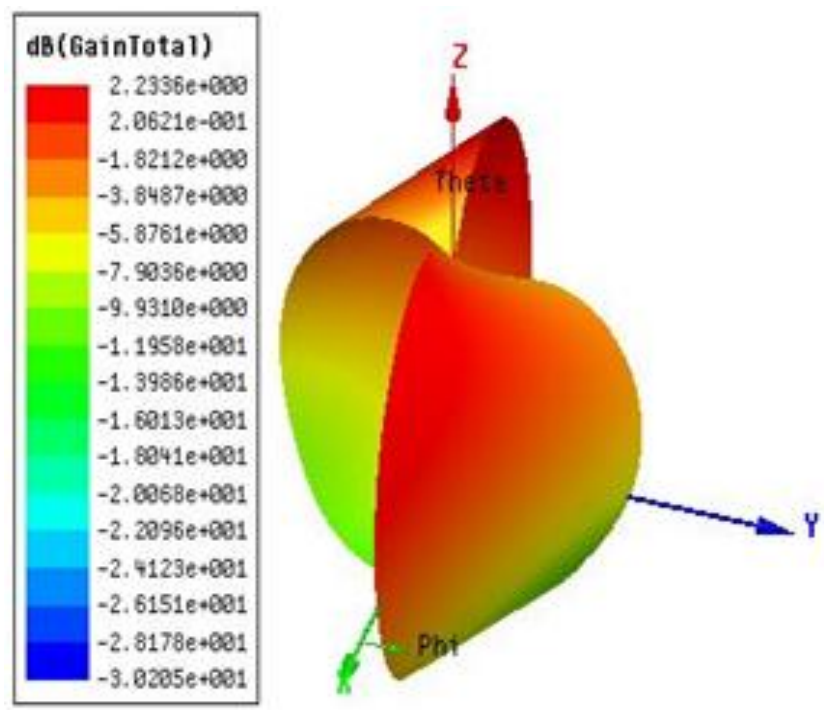

(a)
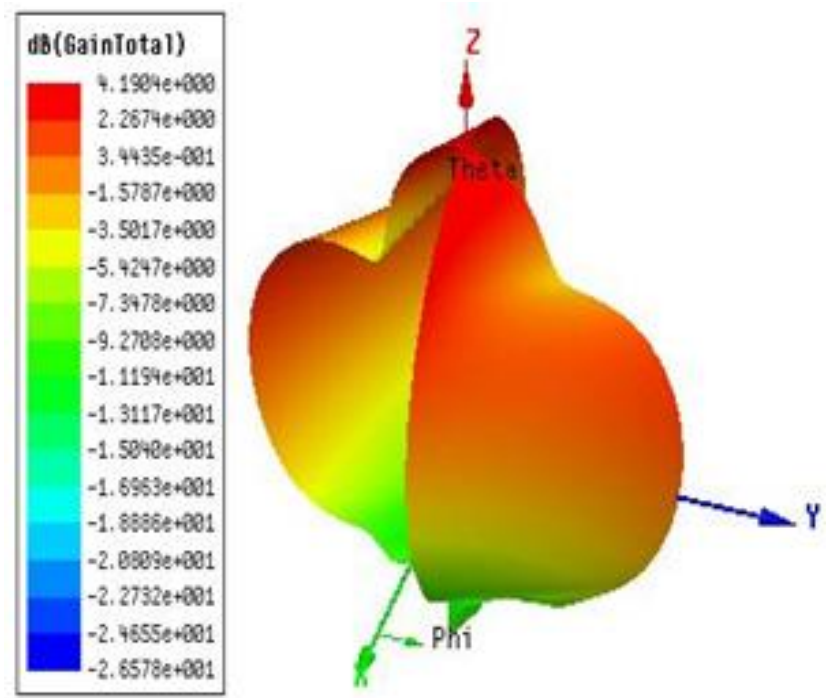

(b) 

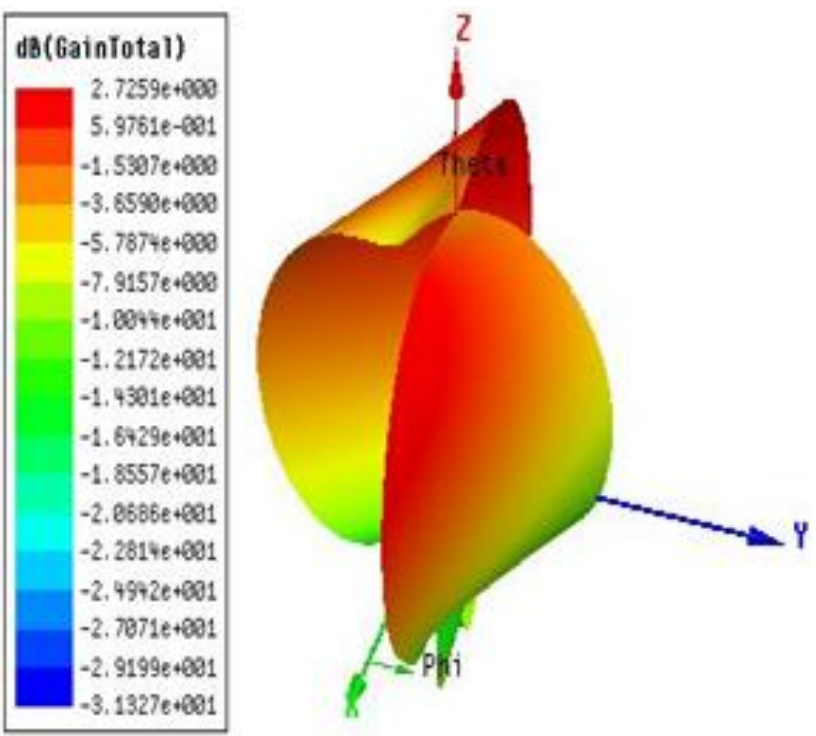

Fig 6: Simulated 3D Radiation pattern of the proposed antenna at (a) $5.55 \mathrm{GHz}$ (b) $6.55 \mathrm{GHz}$ (c) $7.40 \mathrm{GHz}$

\section{CONCLUSION}

In this communication a triple band inverted F-slot antenna for WLAN/WiMAX applications is presented. The measured and simulated results show that the obtained impedance bandwidths are from 5.40-5.60 GHz, $6.45-6.62 \mathrm{GHz}$ and 7.35$7.50 \mathrm{GHz}$ respectively, good enough for WLAN and WiMAX applications. In addition, the proposed antenna has good radiation characteristics and gains in its all operating bands, so it can emerge as an excellent candidate for multiband generation of wireless

\section{REFERENCES}

[1] Howell, J., "Microstrip antennas," IEEE Transactions on Antennas and Propagation, vol.23, no.1, pp. 90-93, Jan 1975.

[2] H. Nornikman, F. Malek, N. Saudin, N. A. Zainuddin, M. Md. Shukor, M. Z. A. Abd Aziz1, B. H. Ahmad, M. A. Othman; "Dual Layer Rectangular Microstrip Patch Antenna with H-Slot for $2.4 \mathrm{GHz}$ Range Applications," 3rd International Conference on Instrumentation, Communications, Information Technology, and Biomedical Engineering (ICICI-BME) 44 Bandung, November 7-8, 2013.

[3] Hari Shankar Singh, Mayank Agarwal, Gaurav Kumar Pande, and Manoj Kumar Meshram, "A Quad Band Compact Diversity Antenna for GPSL1/WiFi/LTE2500 /WiMAX/HIPERLAN1 Applications," IEEE Antennas and Wireless Propagation Letters, Vol. 13, 2014.

[4] Wang Ren, "Compact H-Shaped Slot Antenna for 2.4/5.8GHz WLAN Applications," IEEE International Conference on Multimedia Technology (ICMT), 2010.

[5] M. Siva Ganga Prasad, P. Poorna priya, J. Lavanya, M. S. Rajeev Trivedi, K. Manideep, V. V. Vamsi siva Krishna "Design of dual and triple band antennas using U-slots on stacked patches, " International Journal of Modern Engineering Research (IJMER) Vol.2, Issue.3, May-June 2012.
[6] Ebrahim Sailan Aabidi, M. R. Kamarudin, T. A. Rahman, and Hashimu Uledi Iddi, "Multi-band Circular Patch Antenna for Wideband Application," PIERS Proceedings, Stockholm, Sweden, Aug. 12-15, 2013.

[7] Ahmed Khidre, Kai-Fong Lee, Atef Z. Elsherbeni, and Fan Yang Wide Band Dual-Beam U-Slot Microstrip Antenna; IEEE Transactions On Antennas And Propagation, Vol. 61, No. 3, March 2013.

[8] Kai-Fong Lee, Fellow, IEEE, Shing Lung Steven Yang, Member, IEEE, and Ahmed A. Kishk, Fellow, IEEE "Dual- and Multiband U-Slot Patch Antennas" ,;IEEE Antennas and Wireless Propagation Letters, VOL. 7, 2008.

[9] Aleš ČÁP, Zbyněk RAIDA, Eduardo de las HERAS PALMERO, Roberto lamadrid ruiz,"Multi-Band Planar Antennas: A Comparative Study, " Radio Engineering, Vol. 14, No. 4, December 2005.

[10] K. Li, M. Ingram, and E. Rausch, "Multibeam antennas for indoor wireless communications," IEEE Trans. Comm., vol. 50, no. 2, Feb. 2002.

[11] Sana Arif, Syeda Areeba Nasir, Muhammad Mustaqim and Bilal A. Khawaja; "Dual U-Slot Triple Band Microstrip Patch Antenna for Next Generation Wireless Networks," IEEE International Conference on Sensor Network Security Technology and Privacy Communication System (SNS \& PCS), 2013.

[12] J C. A. Balanis, Antenna Theory Analysis and Design, 2nd ed. Hoboken, NJ, USA: Wiley-Interscience, 2005

[13] D.Wang and Q. Rao, "Integrated design of multiple antennas for WiFi/Bluetooth/GPS mobile communication," in Proc. Prog. Electromagn.Res. Symp., Cambridge, MA, USA, Jul. 2010, pp. 755-758.

[14] Mouloud Challal, Arab Azrar and Mokrane Dehmas, "Rectangular Patch Antenna Performances Improvement Employing Slotted Rectangular shaped for WLAN Applications," IJCSI International Journal of Computer Science Issues, Vol. 8, Issue 3, No. 1, May 2011, pp.254258.

[15] S. Park, J. Lee, J. Lee, and A. S. Kim, "Dual-port LCP multi-band antenna for WiBro/mWiMax MIMO, Bluetooth and GPS applications in mobile phone," in Proc. Antennas Propag. Soc. Int. Symp., Charleston,SC, USA, Jun. 2009, pp. 1-4, 2009.

[16] C. L. Mak, K. M. Luk, K. F. Lee, and Y. L. Chow, "Experimental study of a microstrip patch antenna with an L-shaped probe," IEEE Trans. Antennas Propag., vol. 48, no. 5, pp. 777-783, May 2000.

[17] Mahender, P.; Natarajamani, S. \& Behera, S. K., "Inverted U-Shaped Dielectric Resonator Antenna for WLAN," IEEE International Conference on Communication, Control and Computing Technologies, pp. 9-11, October 7-9, 2010.

[18] Garg, B., Bahl, I. Microstrip Antenna Design Handbook. Norwood: Artech House, 2001.

[19] Wong, K. L. Compact and Broadband Microstrip Antennas. New York: J. Wiley and Sons, 2002.

[20] Ansoft HFSS ver. 11, Ansoft Corporation. Canonsburg. 